\title{
Reported stigma and discrimination by people with a diagnosis of schizophrenia
}

\author{
D. Rose $^{1 *}$, R. Willis ${ }^{2}$, E. Brohan ${ }^{1}$, N. Sartorius ${ }^{3}$, C. Villares ${ }^{4}$, K. Wahlbeck ${ }^{5}$, G. Thornicroft ${ }^{1}$ and \\ for the INDIGO Study Group \\ ${ }^{1}$ Health Service and Population Research Department, Institute of Psychiatry, King's College London, De Crespigny Park, London SE5 8AF, UK \\ 2 Institute of Gerontology, Room 6.27, Strand Building, King's College London, Strand, London WC2R 2LS, UK \\ 314 Chemin Colladon, 1209 Geneva, Switzerland \\ ${ }^{4}$ Department of Psychiatry, UNIFESP - São Paulo Federal University, R. Borges Lagoa, 570, 04038-020, Sao Paulo - SP, Brazil \\ ${ }^{5}$ National Institute for Health and Welfare, Mental Health and Vaasa, Central Hospital, 65320 Vaasa, Finland
}

\begin{abstract}
Aims. This article examines the extent of stigma and discrimination as reported by people with a diagnosis of schizophrenia. The hypothesis is that when people express in their own words the discrimination they experience such discrimination will be found to be widespread.
\end{abstract}

Methods. Seventy-five people with a diagnosis of schizophrenia from 15 different countries were interviewed with a mixed methods instrument to assess reported discrimination. The data were analysed for frequency counts and then a thematic analysis was performed. A conceptual map is provided.

Results. The study was a cross-cultural one but, contrary to expectations, few transnational differences were found. The main hypothesis was supported. Conversely, we found that when participants reported 'positive discrimination', this could as easily be conceptualised as being treated similarly to how others in society would expect to be treated.

Conclusion. Negative discrimination is ubiquitous and sometimes connotatively very strong, with reports of humiliation and abuse. 'Positive discrimination' conversely indicates that people with a mental illness diagnosis expect discrimination and are grateful when it does not occur. The literature on self-stigma is discussed and found wanting. Similarly, the theory that contact with mentally ill people reduces stigma and discrimination is not fully supported by our results.

Received 18 March 2010; Revised 10 September 2010; Accepted 3 November 2010

Key words: Behaviour, consumers', views, discrimination, schizophrenia, stigma.

\section{Introduction}

This paper describes how people with a diagnosis of schizophrenia experience discrimination. Most work in this field reports public attitudes towards those with a mental illness diagnosis and not the experiences of the targets of discrimination themselves. Studies that have considered the views of people with personal experience of mental illness typically focus on perceived stigma (i.e. the view that the public hold stigmatising attitudes) with a much lower proportion of studies focusing on experiences of stigma and discrimination (Brohan et al. 2010). We hypothesise that people who are the targets of discrimination will routinely experience the consequences of negative attitudes that have been found to characterise general

* Address for correspondence: Dr Diana Rose, Institute of Psychiatry, King's College London, PO Box 34, De Crespigny Park, London SE5 8AF, UK.

(E-mail: d.rose@iop.kcl.ac.uk) public. We further hypothesise that experiences of positive discrimination will be uncommon.

Early investigations identified entrenched negative views towards people with severe mental health problems. Cumming \& Cumming (1957), in the USA, carried out an educational project with residents of a community where a hostel for ex-psychiatric patients was due to be built. However, the attitudes of the residents were so negative that the experiment had to be abandoned. The majority of recent research indicates that the situation has not substantially improved (Hayward \& Bright, 1997; Angermeyer, Beck \& Matschinger, 2003; Department of Health, England, 2003). Further, stigmatising attitudes have been found to be far stronger against people with a diagnosis of schizophrenia than against people with other diagnoses (Angermeyer, Beck M, Matschinger, 2006). Most of this work uses a social survey methodology, sometimes with vignettes and sometimes Likert scales alone. Social distance scales (Star, 1955) sometimes replace Likert scales. 
This survey work has little theoretical foundation. However, there have been modest conceptual developments. Corrigan et al. (2003) reinstated the work of the sociologist Scheff (1966) to consider that the attributes to which stigma is assigned are not necessarily intrinsic to mental illness. A mental illness diagnosis is, according to Scheff, a label consequent on transgressing normative social rules and the dominant moral order. It is the label that attracts stigma and not the behaviour of the person as such. This label stems from psychiatric diagnostic categories, the assignment of which confers the status of mental patient. Elsewhere, we argue that the allocation of a psychiatric label is a pivotal point in the life of the person to whom it is assigned (Rose \& Thornicroft, 2010). Link \& Phelan (2001) further argue that concepts of stigma must include the effects of power and structural discrimination. People with a mental illness diagnosis are not in a relation of power equality with respect to those who treat them. Neither, often, are they in a relation of equality with respect to other people in society and the structural dimensions of society. These concepts of labelling and power inequity provide the conceptual underpinning for this paper. In addition there has been increasing emphasis on the behavioural and not just the attitudinal aspects of stigma (Thornicroft, 2006).

In our study, we included respondents from 15 countries. There are a few papers that investigate the extent of stigma and discrimination against people with enduring mental health problems across nations or regions. Schomerus et al. (2006) examined public attitudes in Novosibirsk (Russia), Bratislava (Slovakia) and large German cities with the purpose of investigating whether psychiatric reforms in the form of closure of large institutions improved public attitudes. On the whole, they found no difference between the three sites. This disconfirmed their hypothesis and demonstrated entrenched transnational stigma towards those with mental health problems. Conversely, Kurihara et al. (2000) found less discrimination in Bali (Indonesia) than in Tokyo (Japan) and attributed this to the lack of institutional beds in Bali meaning that the population had more contact with people with mental ill health. The evidence is therefore ambiguous as to the place of institutional practice and reform. However, in no case were persons with a diagnosis of mental illness themselves asked about the effects of this.

Recently, research has started to be carried out on the views of people with schizophrenia themselves on the discrimination they face (Schulze \& Angermeyer, 2003; Gonza'lez-Torres et al. 2006; Cechnicki et al. 2010; Buizza et al. 2007). Interestingly, most of these studies adopt a qualitative methodology. Angermeyer et al. (2004) used the findings of the focus group study of
Schulze \& Angermeyer (2003) to construct a quantitative scale although with a very different population.

All the qualitative studies are part of 'Schizophrenia Open the Doors', the World Psychiatric Association Global Programme against Stigma and Discrimination because of Schizophrenia, the argument being that qualitative methods are best suited to exploring subjective experience. Stigma and discrimination have been found to be endemic in all these investigations. In most of this research, relatives and sometimes mental health staff have also been included and, problematically, the reports are weighted towards these 'collaterals' views of what they think people with the diagnosis experience with respect to stigma and discrimination.

\section{Method}

\section{Instrument}

The study used a mixed methods scale called DISC (Discrimination and Stigma Scale v10) developed as part of the International Discrimination and Stigma Outcomes (INDIGO) project. Because of the wide range of languages represented in the sample, a consistent translation and cross-cultural adaptation procedure was adopted to ensure that the different language versions of the DISC 10th version were as comparable as possible. The instrument was translated from English into the local (target) language using a forward and back translation approach. A reconciliation focus group with 6-10 local people with a diagnosis of schizophrenia was conducted in each site, to make sure that the scale, in their own language, was comprehensible and easy to respond to, before the final version was established (Sartorius \& Kuyken, 1994).

There are 42 domains in the DISC ranging from relationships with friends, family, neighbours and intimate relationships including marriage and parenthood through to employment and public affairs. There is also a question about treatment by healthcare staff, including mental health professionals. In addition, there are questions that are intended to tap self-stigma or anticipated discrimination by asking respondents how far they had stopped themselves from undertaking important activities, such as applying for a job or embarking on intimate relationships. The full instrument may be obtained from the authors.

The DISC is a mixed methods instruments attempting as comprehensive as possible an investigation into experiences of discrimination on the part of people with a diagnosis of schizophrenia. It was originally used in 27 countries with 732 participants. The quantitative data are scored on a 7-point Likert scale in answer to a question about being treated differently because of a diagnosis of schizophrenia. The anchor points are 'strong 
disadvantage' to 'strong advantage' with 'no different treatment' as the mid-point (Thornicroft et al. 2009).

In the DISC, the qualitative component comes before the Likert scale for each item. Respondents are asked, for each domain, to give an example of how they have been treated differently (or not) from other people because of their diagnosis of mental illness. The responses elicited to these questions make up the qualitative dataset. Following this, the respondent is asked to complete the Likert scale for each domain.

\section{Sample}

We analysed five transcripts from each of 15 sites. The sites were chosen to represent the full INDIGO study and included 'old' EU countries, newly acceded countries, candidate countries for the EU and countries outside the EU in various stages of economic development. There was no significant difference in the distribution of EU status (categorised as five groups: (1) Pre 2004 entry; (2) Post 2004 entry; (3) Present applicants; (4) Non-EU high income; and (5) Non-EU low or middle income) between the 15 countries included in the analysis and the 12 countries not included in the analysis $\left(X^{2}=4.99, \mathrm{df}=4, p=0.29\right)$. This suggests that the included sites are representative of all sites involved in this study. The participating countries were: Brazil, Bulgaria, Cyprus, England, Finland, France, Greece, Italy, Lithuania, Malaysia, Romania, Slovakia, Slovenia, Turkey and the USA. Local interviewers were asked to randomly select respondents for the qualitative analysis meaning, in effect, that they tape-recorded the interviews. All sites were cities or centres of large population and this means that most of those interviewed were living in urban settings.

As Table 1 shows, there were no significant differences between the participants who were included in the qualitative analysis and the rest of the INDIGO sample on any of the socio-demographic characteristics with the exception of main type of mental healthcare. This was further investigated by considering only the data from the countries which were included in the qualitative analysis. As mentioned, 27 countries took part in the overall INDIGO study; however, only data from 15 of these countries was included in the qualitative analysis to keep data quantity manageable. When data from the included countries were considered, the association between inclusion in the qualitative analysis and main type of mental healthcare is no longer significant $\left(X^{2}=8.69, \mathrm{df}=4, p=0.069\right)$. This provides evidence to suggest that there is no systematic bias in any of the socio-demographic variables including main type of mental healthcare between the transcripts received from the included nations and the remaining data from these nations. It remains the case, however, that most people interviewed were receiving out-patient care and therefore were likely not acutely unwell at the time. This is important as Buizza (2007) found that with a sample largely made up of participants on a rehabilitation ward, most stigma was reported in relation to mental health services. However, this was more marked among family members than service users.

\section{Data collection}

The 75 participants were interviewed with the DISC in a one-to-one, face-to-face format. The interviewers were in a range of different mental health professionals or researchers from Non-Governmental Organisations. The interviews were audio-taped. They were then transcribed and translated into English at the local site and sent to the coordinating site (London, England) for analysis in the form of Microsoft Word documents.

\section{Analysis}

The transcripts were highly structured according to the format of the DISC, and contained the verbatim response of each participant to the questions, along with the Likert scale response.

The qualitative data handling programme NVivo 2 (QSR, 2002) was used to aid the storage, structure and analysis of the transcripts.

The verbatim responses to the questions about experiences of discrimination were subject to a process of open coding (Strauss \& Corbin, 1990). A code-book was developed to include emergent themes. Detailed memos were created in NVivo to keep a record of coding decisions as they were made. Chunks of text were coded under relevant headings so that responses were grouped together if their meanings were the same. This was done iteratively and the coding scheme revised if new themes emerged later in the analysis. Using the constant comparison method (Strauss \& Corbin, 1990), we examined positive and negative examples to see how these examples differed in terms of their meanings. Examples of themes, along with their frequency, are presented here. A conceptual map was constructed to visually represent the relationships between themes and sub-themes (Boyatzis, 1998; Braun \& Clark, 2006), as well as building a general model, the use of NVivo allowed examination of patterns across questions and of similarities and differences by INDIGO site.

Two of the authors engaged in a process of multiple coding (DR and RW). Where there were discrepancies, they were discussed and a decision made on how best to code the relevant text (Barbour, 2001). 
Table 1. Comparison of socio-demographic characteristics of those included with those not included in the qualitative analysis

\begin{tabular}{|c|c|c|c|c|}
\hline Item & $\begin{array}{l}\text { Response } \\
\text { Options }\end{array}$ & $\begin{array}{l}\text { Included in qualitative } \\
\text { analysis }(n=75) \%\end{array}$ & $\begin{array}{l}\text { Not Included in qualitative } \\
\text { analysis }(n=651) \%\end{array}$ & $\begin{array}{l}\text { Significance level } \\
\text { of statistical test }^{t, \ddagger}\end{array}$ \\
\hline 1. Gender & Male & 60.0 & 62.1 & $p=0.709, \mathrm{NS}^{\S}$ \\
\hline & Female & 40.0 & 37.9 & \\
\hline 2. Age & & $\begin{array}{l}\text { Median (Range) } \\
\quad 37(19-51)\end{array}$ & $\begin{array}{l}\text { Median (Range) } \\
\quad 38(16-76)\end{array}$ & $p=0.100, \mathrm{NS}$ \\
\hline 3. Years of education & & $\begin{array}{l}\text { Median (Range) } \\
\quad 12(5-19)\end{array}$ & $\begin{array}{l}\text { Median (Range) } \\
12(3-24)\end{array}$ & $p=0.235, \mathrm{NS}$ \\
\hline 4. Currently employed & $\begin{array}{l}\text { Yes } \\
\text { No }\end{array}$ & $\begin{array}{l}65.3 \\
34.7\end{array}$ & $\begin{array}{l}70.8 \\
29.2\end{array}$ & $p=0.351, \mathrm{NS}$ \\
\hline $\begin{array}{l}\text { 5. Years since first } \\
\text { contact with } \\
\text { mental health } \\
\text { services }\end{array}$ & & $\begin{array}{l}\text { Median (Range) } \\
12(0-34)\end{array}$ & $\begin{array}{l}\text { Median (Range) } \\
13(0-46)\end{array}$ & $p=0.282, \mathrm{NS}$ \\
\hline $\begin{array}{l}\text { 6. Main type of mental } \\
\text { healthcare }\end{array}$ & $\begin{array}{l}\text { In-patient } \\
\text { Out-patient } \\
\text { Home } \\
\text { Day care }\end{array}$ & $\begin{array}{l}5.3 \\
65.3 \\
1.3 \\
25.3\end{array}$ & $\begin{array}{l}24.0 \\
52.2 \\
7.1 \\
16.1\end{array}$ & $p<0.001$ \\
\hline $\begin{array}{l}\text { 7. Ever received } \\
\text { compulsory } \\
\text { treatment }\end{array}$ & $\begin{array}{l}\text { Yes } \\
\text { No }\end{array}$ & $\begin{array}{l}46.7 \\
53.3\end{array}$ & $\begin{array}{l}55.5 \\
44.5\end{array}$ & $p=0.092, \mathrm{NS}$ \\
\hline 8. Know your diagnosis & $\begin{array}{l}\text { Yes } \\
\text { No }\end{array}$ & $\begin{array}{l}18.9 \\
81.1\end{array}$ & $\begin{array}{l}16.2 \\
83.8\end{array}$ & $p=0.513, \mathrm{NS}$ \\
\hline 9. Agree with diagnosis & $\begin{array}{l}\text { Agree } \\
\text { Disagree } \\
\text { Unsure } \\
\text { Don't know }\end{array}$ & $\begin{array}{l}69.6 \\
8.7 \\
5.8 \\
15.9\end{array}$ & $\begin{array}{l}62.3 \\
16.5 \\
7.9 \\
13.4\end{array}$ & $p=0.313, \mathrm{NS}$ \\
\hline
\end{tabular}

Notes:

${ }^{\dagger}$ Due to the non-parametric distribution, the Mann-Whitney $U$-test was conducted in the case of continuous data (age, years of education, years since first contact with mental health services). The chi-square test was used in the case of categorical data (all other variables).

${ }^{\ddagger}$ All hypotheses are two tailed.

$\S_{\mathrm{NS}}=$ non significant

Thematic analysis is an interpretive act. Ahuvia (2001) argues that even content analysis should move in this direction. Ahuvia (2001) also introduces the concept of 'focal interpreters', that is, classes of coders who have different interests in a text. For example, coders could be drawn from the authors or the intended audience of a text. According to Ahuvia, researchers cannot be 'focal interpreters' as they are removed from the authors/intended audiences of a text. However, this ignores the possibility that researchers may be part of the community from which qualitative data are drawn. In our case, one of the authors (DR) is a mental health service user who has experienced stigma and discrimination and so, we would argue, qualifies as a 'focal interpreter'. The argument is that this brings the researcher closer to the intended meanings of the participants.

\section{Results}

\section{Transnational patterns}

We found surprisingly few cross-cultural differences in experiences of discrimination and those that we did find were difficult to interpret. There are two possible reasons for this. One is that stigma and discrimination are indeed transnational as some of the literature suggests. Falk (2001) argues that ascriptions of mental illness constitute the 'ultimate' stigma. Alternatively, five transcripts per site is too small a number on which to base comparisons in which case our study must be seen as a global one. Therefore, we shall say no more about cross-cultural differences in this paper but will give the nation of each of the participants whom we quote in case the reader can detect differences that we have missed. 


\section{Thematic analysis}

This section gives the results for the data as a whole. Table 2 gives a simple frequency count of the main categories that emerged in the data. The cut-off point for inclusion in this section was 15 instances.

Most of these themes were not tied to specific domains in the DISC but were used to exemplify discrimination experienced in several domains. A conceptual map was constructed and is shown in Fig. 1. The following presentation of results along with examples is organised according to the conceptual map.

\section{Shunned}

In the centre of the conceptual map is the dominant interpretive theme 'shunned'. This theme occurred in answers to ten different questions, including the most obvious one which asked about being shunned or avoided. The examples given by the participants involved being shunned by friends, being ignored by neighbours, being isolated at school and being ignored by their family, all because of their diagnosis of mental illness. Most instances of this were interpersonal rather than public or structural (e.g. employment and political life).

Yes. All my friends turned away of me. They start to avoid contacts with me. They just stopped to communicate with me, broke the relations. My illness was strong disadvantage for me. (Lithuania 01)

Well, I think I became ill when I was in the lyceum (high school). Then, the other students did not include me in their groups. One of my teachers used to be very sarcastic and make fun of me while the other classmates would laugh. My classmates did not come to my birthday and they did not invite me to theirs. (Cyprus 03)

At the beginning of my illness, when my neighbours found out about it, they said: 'This lunatic has to be left alone'. (Romania 04)

Table 2. Frequency of themes

\begin{tabular}{lc}
\hline Theme & Frequency \\
\hline Shunned & 103 \\
Isolates self from society & 61 \\
Entitlements because of MI & 39 \\
Mocked & 38 \\
Can only be with other service users & 37 \\
Abuse & 34 \\
Lack of understanding & 32 \\
Well meaning, but negative & 29 \\
Relationships too emotionally demanding & 29 \\
Limited romantic prospects & 20 \\
Side effects of medication & 18 \\
\end{tabular}

Some participants tried to understand or make allowances for the reactions of other people:

Sometimes it's hard to tell why you're being excluded from things, it could be because you're junior, or not work area, so you have to be careful about these things. (England 05)

For others, this avoidance was something too upsetting to speak about:

Some do. It matters a great deal. I can't talk about it now. (Slovenia 03)

Two important sub-themes are being mocked and abused. Although lower in frequency counts than some other themes, they have been highlighted in the conceptual map because of their connotative and emotional power.

\section{Mocked}

This sub-theme includes mocking, teasing, being humiliated, being called names and being verbally abused. The theme occurred in relation to friends, neighbours, education, family, keeping a job and public transport. Unlike the preponderance of interpersonal examples in the dominant theme 'shunned', there was some evidence of being mocked in public life. Being treated in this way led two participants to leave education without finishing.

I have been attacked verbally and mocked, for example on the workplace they said I was a dullwitted, that I did not understand nothing, that I was a refuse of the society. (Italy 03)

I stayed with my aunt only for a month, because she didn't want anymore; she used to call me 'crazy'... It is not easy! She said to my little cousin that I was crazy; he would call me that, too, so because of that, I left. (Brazil 05).

\section{Abused}

Abuse is a very strong form of discrimination. In fact, the word 'discrimination' does not capture it semantically. Participants reported being abused, physically and sexually by family, friends, in intimate relationships and by the police, in relation to their safety and by mental health staff. They reported being beaten or struck by various family members, by former friends, by other service users, by strangers, by the police and by mental health staff. Three participants said that they had experienced sexual violence or abuse, one from a mental health professional. Two participants reported witnessing mental health staff abusing other service users.

Interviewer: Have you been treated differently from others in the domain of your personal security because of the diagnosis of a mental illness? 


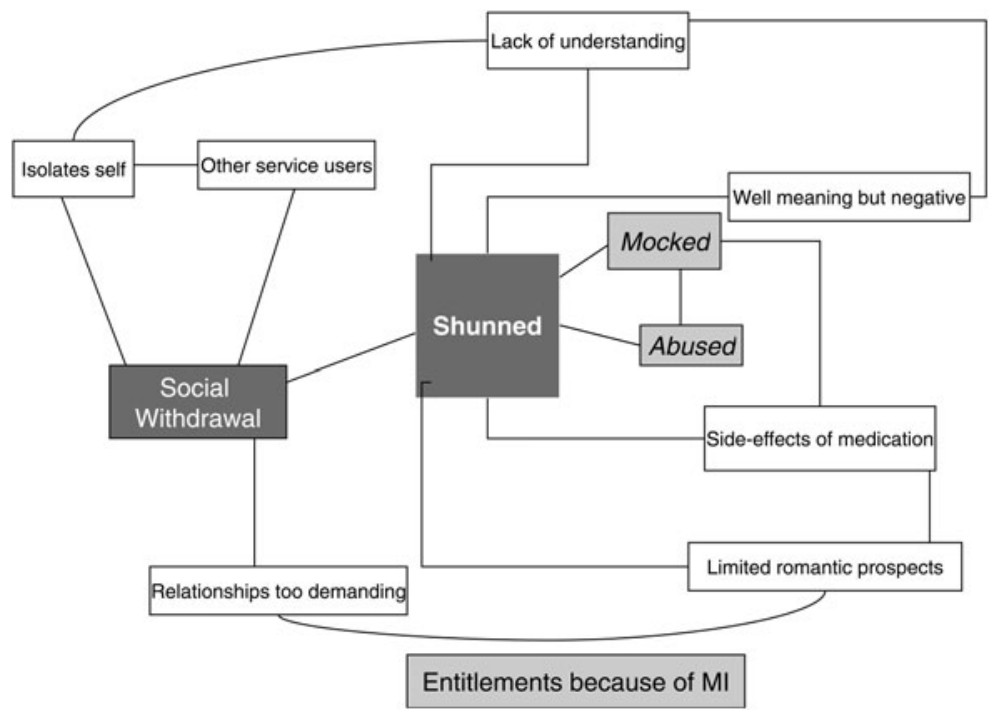

Fig. 1. Perspectives on Discrimination by People with a Diagnosis of Schizophrenia.

For example, has anyone tried to attack you or rape you?

Participant: Yes, let's see where I am going to put this one. I think it is -1 . You know why? I had some friends since childhood and when I became ill they came and attacked me. They tried to beat me up and they did. Fortunately, I was not seriously injured. (Cyprus 05)

It happened in the hospital. I don't want to mention the ward. I was 'on remote control' because of the medication, when somebody from the medical staff, I don't know if he was a psychiatrist or a psychologist, asked to see me in his office. He kissed me and he touched me and he asked me to masturbate myself. I was so submissive because of the medication that I did it. (Romania 02).

\section{Lack of understanding/well meaning but negative}

When participants talked of people not understanding them or being well-meaning but with negative effects they did not use the powerful language of the two subthemes analysed above. In some cases, they expressed understanding of why others might act like this. However, they still saw this as being 'treated differently' and as a disadvantage of their diagnosis. They still experienced it as a form of discrimination.

\section{Lack of understanding}

Participants talked about people who did not understand their illness in both their personal (friends, dating and family) and public (neighbours, education and physical healthcare) lives. Examples of this lack of understanding are that people did not understand that the participant could not help some of the ways they behaved, people thought the participant would be violent and some people misunderstood the cause of the illness (socialising too much, a weak character, laziness or political beliefs). Some of the health professionals that participants were in contact with did not understand the illness, for example, general practitioners. One participant thought that members of the clergy would understand mental illness, but their experience of this was otherwise.

It does show you just how even the informed middle classes, even you (interviewer), know about mental illness. Everybody knows very little about it. Because most of the publicity is negative, about violence and so on. There's no information for people, is there? And also they don't like talking about it. (England 05)

My father thinks that I am irresponsible because I am not working and I am not like the others. (Greece 01)

\section{Well-meaning but negative}

There are instances of people treating the participant in a way that is well intentioned, but is experienced negatively by the participant. For example, participants felt over-protected in several areas of their lives: by friends, by partners, by family and by work colleagues. These were examples of people thinking the participant needed to be shielded from some of the more difficult or stressful aspects of life and work, because of their mental illness.

Participant: Well, my closest relatives like to decide for me, all the time. Sometimes it's almost like I was declared incapable of managing my own affairs. 
Interviewer: Ok. In what way do you feel like you were declared incapable of managing your own affairs?

Participant: Well, if I'd like to purchase something or build something they always pull the brakes, no matter how important it would be for me to fulfil my plans... You see, it's terribly important for me to do woodwork and build things with my own hands. Because that's my profession. (Finland 03)

The issue where most of the comments arise is that of family with the most frequent comments being about being over protected. It seems that people who care for the participant attempt to protect or assist them, but the participants wish to have more autonomy and experience this as disabling.

\section{Side effects of medication}

Participants were not directly asked about the effect taking psychotropic medication had on their lives, yet the negative side effects of this emerged as an important sub-theme of the dominant theme 'shunned'. In some cases, visible side effects were seen as the cause of others avoiding them. This theme involved nine domains including intimate relationships, education, driving licence, physical health, dental health, starting a family, having the diagnosis, stopping self from work/study and stopping close personal relationships. In all of these domains, the participant has been prevented from doing something, had prevented themselves from doing something or had some other difficulty directly caused by their medication.

For one participant, the side effects of medication negatively affected their intimate relationships because their libido was reduced. In another case, the visible side effects made their partner look down on them. A third participant said that they cannot have relationships at all because of the medication. The side effects of medication made participants unable to study, because they could not concentrate, stopped them from applying for work, because they could not see very well and prevented them from driving. Physical side effects of the medication included weight gain, diabetes and tooth decay. Some participants had been prevented from starting a family because of the medication; the participant themselves, their family, their work colleagues and their doctor having all expressed concern about the effect of medication on a developing baby.

Interviewer: Have you been treated differently in relation with your education?

Participant: To such an extent that my medication prevented me from being adequate. I think that most of the time, from the very beginning, most of the time I slept. I was just not able to study. (Bulgaria 04)

\section{Social withdrawal}

The second interpretive theme in our data is 'social withdrawal'. There is a two-way relationship between this and 'shunned'. Being shunned may lead to social withdrawal but social withdrawal may lead the individual to actively cut themselves off from society. The commonest form of social withdrawal is isolation from the rest of the social world.

\section{Isolates self from society}

In eight different domains in the DISC, participants gave responses that were indicative of a certain amount of active withdrawal from society. All of them involve personal life. Participants described not wanting to be involved in romantic relationships, drifting apart from their friendships, avoiding other people, not going outside and avoiding social situations. Many of the responses in this category are simply statements that the respondent does not do something, e.g. go out, look for friendships. Others refer to lack of confidence. One respondent describes embarrassment in how to talk about their diagnosis of schizophrenia:

Participant: When I first got to [city] I met a girl, some other people I've met. She knew I had a problem like this but I liked her a lot but I couldn't, I just didn't keep in touch, she went back to [country] and stuff. A few things that happened like that where I could extend myself further but it was early on when I didn't want to, I didn't know what to say. I felt awkward, so awkward that I didn't know how to bring it up. I just didn't do anything about it and I let the relationship go.

Interviewer: And it was in part because you didn't know what to say about your mental illness?

Participant: Yeah, pretty much. That was early on, when I first got sick. (USA 05)

Other respondents describe isolating themselves because they are afraid that they will be rejected if they disclose their diagnosis:

I avoid from starting a personal relationship because I fear that my partner would say 'you are ill and that's why you speak like that' even if I'm right. (Turkey 02)

But I try not to speak too much about myself. I am afraid later the rumour that I had been staying in this ward can get spread. (Lithuania 04)

Social withdrawal is sometimes seen as a 'negative symptom' of schizophrenia, thus medicalising behaviour. However, the quotations above suggest that people with this diagnosis have good reason to avoid normal social life because of the negative consequences that they anticipate. 


\section{Can only be with other service users}

Linking with the social isolation experienced by the participants, and as a consequence of the shunning they experience, participants often described their friendships with other service users. The importance of peer support is not often recognised in the literature but was highlighted by Rose et al. (2009) in a study on continuity of care. This study was carried out by service user researchers. Further, the importance of peer support is beginning to be recognised in the 'recovery' literature (Slade, Amering \& Oakes, 2008; Slade, 2009). For our participants, it seemed easier to form friendships with other service users because they did not discriminate against them. There was no need to conceal the diagnosis from these people. This indicates that participants still wanted a social life but that it was safer to confine this to those with similar experiences. One participant even said, in response to the domain marriage, that they could only have married another service user because nobody else would have them

Interviewer: In general, to what extent do you feel that you are being avoided by people who know that you have a mental illness?

Participant: I think a little bit.

Interviewer: And your example?

Participant: Hmm...People who are ill themselves and know that I am ill do not avoid me. But those who are not ill but know that I am ill do avoid me. (Cyprus 01)

There are two sub-themes that have links to both main themes and inter-link themselves. These are 'relationships too emotionally demanding' and 'limited romantic prospects'. The former has a stronger semantic linked to the dominant theme itself.

\section{Relationships too emotionally demanding}

Some participants avoided certain circumstances (e.g. marriage and having a family) because they believed that they would be too stressful. Other participants simply described the difficulties of interpersonal relationships when one has a diagnosis of schizophrenia, e.g. in working life or in social friendships.

Interviewer: Do you want to marry?

Participant: In the old days I used to say to a teacher of mine of the 5 th grade that the most important thing in my life was my emotional side. For me, the professional side comes as a second plan. I think that after having this messy relationship I started not giving as much value to this emotional side, and then after the diagnosis, it became worse, you know.

Interviewer: And when you talk to people about your willingness to marry or not, how do they react?

Participant: I have already told my psychologist and sometimes to some friends, I say that I feel it is complicated, it is very difficult for me. The wish I had I do not have anymore. (Finland 03)

\section{Limited romantic prospects}

The previous sub-theme was focused on the participants' beliefs that they themselves would find certain relationships too demanding. This functions as an example of social withdrawal. However, in the subtheme 'limited romantic prospects', there was a sense of this being imposed on them by discriminatory structures. Often in response to the questions about romantic relationships participants stated that they had very limited prospects. For instance, three people said they could not get a date because of their diagnosis; nine people said that they could not have a relationship because of their illness and four people said that no-one would marry them. Another participant said that enquiries had been made on their behalf about an arranged marriage, but their prospective in-laws had refused the match because of the mental illness.

Some participants had experienced actual discrimination:

Once, an aunt of mine tried to set me up with somebody. As soon as he and his family met me they told me that I was not good enough for their son and that hurt me very much. (Cyprus 01)

Other participants avoided intimate relationships because they expected rejection, as indicated above:

I cannot be with a person without him knowing that I have a problem, it is not a huge problem, but it is a problem. I will have to take drugs my whole life, so, I think that this complicated, I feel insecure to disclose to the person and the person might become frightened and disappear and I then will suffer, so, I never more had a relationship, never more I was open to any relationship. (Brazil 04)

\section{Entitlements because of mental illness}

Some participants were entitled to many free services from their governments because of their mental illness. For example, free travel, disability pension or benefits and free medical treatment. Other benefits mentioned were that some participants had obtained their housing because they had schizophrenia, and one person had obtained a special loan because of their illness. This is a theme on its own in the conceptual map as it has no obvious link to the other themes or sub-themes.

Interviewer: Have you been treated differently from other people in your housing because of your diagnosis of mental illness?

Participant: No, I live in a housing association, [name of housing association] and I get a special 
flat because I'm a special needs person so it's made no difference. Actually it's been an advantage.

Interviewer: An advantage? two.

Participant: Yeah so I would say at least plus

Interviewer: Ok, in what way has it been an advantage?

Participant: As I said, [city] and [housing provider] house me and since I'm a special needs person I get new flat, my flat was a new flat I'm the first person to live there and it's quite well equipped and I don't pay for water I just pay for rent, I don't pay for water or furniture I just pay rent and my gas and electricity so it's obviously been plus three possibly because I get a special flat.

Interviewer: So where would you rate it?

Participant: Plus three.(England 05).

I have to say I had a big advantage because thanks to my diagnosis I obtained a disability pension. (Italy 05)

However, another person said:

They don't know the diagnosis, they only know that it's a 'therapeutic flat'; it's just the kids, they say 'it's the crazy house', they use the ringbell and sometimes throw balls on the windows. (France 05)

This last example was eventually coded under 'mocked'.

\section{Positive discrimination}

There was an opportunity in this study for participants to talk about ways in which their diagnosis of schizophrenia had positive consequences for them. As this occurred much less frequently in the transcripts, these are not part of the conceptual map except under the heading of 'entitlements' which, as we have seen, could be ambiguous. However, there were instances where having a diagnosis of schizophrenia conferred real benefits. These were in domains such as welfare benefits and housing. There was also an example from education:

During the last year at the Higher School I was treated at the psychiatry for 5 weeks. On my return to school I was offered an individual studying plan and I've successful graduated. (Slovakia 03)

However, other instances which were coded as positive discrimination seemed, on further examination, to be rather different. Some examples follow:

My neighbours are nice to me. (Greece 03)

$\mathrm{He}^{\prime} \mathrm{s}$ wanting to carry on [the marriage]

because he thinks that I need looking after. (England 05)

Interviewer: Do your friends know that you have this illness?

Participant: Some of them know, those are my closer friend. They accepted me well. (Malay 01)
But in some respect I don't think that anybody has actually been mean to me. (Finland 01)

Yet, I have been out with nice people as well who helped me without asking for something in return from me. (Cyprus 01)

After I have illness, I did apply for work. I got the job and it was partly due to the help from my father. (Malay 03)

As long as I know, the person I had more contact with was my girlfriend, and she has never demonstrated this ... although she had learned about the disease, I taught her a little. .I was at the beginning of the disease, but she considered me a normal person. I believe she has never treated me differently. (Brazil 02)

I go often to the dentist and he is nice to me. (Greece 02)

I am usually teacher in schools or university (Interviewer's comment: 'he really sometimes gives lectures at university'). So I am treated very positively because of my illness. They treat simple achievement like strong advantage. (Lithuania 02)

It is interesting how often the word 'nice' appears in these examples. Even instances where a father helps a child to find a job are hardly specific to mental health. If positive discrimination is the 'opposite' of negative discrimination then this is not the case here. The negative themes that emerged from the data were strong in their connotations - shunned, mocked and abused. The 'positive' examples concern people responding to the participant in a way that anyone would expect to be treated in a civil society - nicely, with kindness and with respect. It is interesting in the last example that the interviewer feels the need to say that the participant 'really' teaches in a university, presumably in case readers see this as a delusion!

The references to 'positive discrimination' came from the respondents themselves when they marked the Likert scales. They said their diagnosis was an 'advantage' in relation to some domains although it could be argued that, in fact, their experience was of 'no different treatment' - the mid-point on the Likert scale.

\section{Discussion}

This study is innovative in two ways. First, it is unusual for stigma research to focus on discrimination, that is, on the behavioural aspects of stigma. Rose et al. (2007) reviewed 54 papers looking at public perceptions of risk and dangerousness from people with mental ill health. Risk and dangerousness are very strong properties of stigma. Only three of these studies focused on behaviour and in two of these actors were used to play the role of a person with mental ill health. Second, the INDIGO project is focused firmly on the experience of mental health service users who have a 
diagnosis of schizophrenia and there are relatively few direct published reports of the experience of people with this diagnosis in relation to discrimination. It might be argued that this is one step removed from actual experience as our data are actually 'reported' experience. However, this is the closest any analysis is likely to get. Even if we took an ethnographic approach and observed behaviour the presence of the observer would likely change the behaviour of others towards the person with schizophrenia.

\section{Negative discrimination}

People with a diagnosis of schizophrenia report discrimination in most domains of life. However, this appears to be particularly acute in the more personal domains such as friendships, family, dating, intimate relationships and marriage. This finding is consistent with those of Schulze \& Angermeyer (2003), who identified a domain of 'interpersonal interaction' as the dominant form of discrimination reported by their participants. Most of the examples cited in this paper and that of Buizza et al (2007) (who strangely identified almost exactly the same themes from a different population to that of Angermeyer \& Schulze, 2003), would come under our theme 'shunned'. Some examples in these two papers could be interpreted as instances of the theme 'mocked', but this is not emphasised by these authors who appear to prefer a more anodyne label.

Many nations and supra-national bodies now have anti-discrimination legislation for people with disabilities. For example, in the UK, there is the Disability Discrimination Act. But such legislation generally covers public life such as employment and public services. It would not be possible to legislate for improved treatment in the domains of personal life. Strategies here must rely on more general anti-stigma and antidiscrimination campaigns, and on a changing public climate that makes disclosure of the more severe forms of mental ill-health more common and acceptable. However, to date, these have not been notably successful. Furthermore, it is not clear that anti-discrimination legislation on grounds of disability has much teeth when it comes to mental health as the laws are generally framed in terms more applicable to those with physical disabilities.

\section{Contact}

Some authors (Link \& Cullen, 1986) suggest that 'contact' with people with mental illness reduces stigma. This 'contact hypothesis' has been examined in laboratory experiments and naturalistically (Kolodziej \& Johnson, 1996). However, most of these empirical studies suffer from lack of a follow-up period. Our data do not necessarily support a straightforward interpretation of the social contact hypothesis. In the eyes of our participants, it was those with whom they had the most contact who discriminated most strongly against them. It was family, friends and neighbours from whom they experienced the strongest discrimination. On the other hand, 'social withdrawal' means that domains such as the family become much more important for a person with schizophrenia and so their lives may revolve around intimate relationships that then become the crucible of difficulties.

\section{Self-stigma}

The DISC contains domains covering both actual experienced discrimination and 'self-stigma'. The latter is tapped by asking whether the respondent has ever stopped themselves from doing something because of their mental health problems. The question arises why people would do this. The survey studies reviewed in the Introduction take the form of asking the public or sub-sections of the public, about their attitudes to people with mental ill health. In terms of asking people with mental health problems themselves about stigma and discrimination, most work has revolved around the concept of 'self-stigma' (Link et al. 2001; Corrigan et al. 2003). These concepts refer to personal reactions to stigmatisation and generally focus on attributes such as depression and low selfworth (Markowitz, 1998).

The self-stigma literature is a socio-psychological one and thus focuses on the internalization of social actions to produce certain psychological states, in this case negative ones. However, the concept of selfstigma is not the only way to interpret our results. In our data, it often seemed that respondents stopped themselves from, for example, embarking on intimate relationships because they anticipated discrimination. They may never have experienced actual discrimination in this domain but were certain that should they even try to embark on an intimate relationship, or apply for a job, then they would be rejected because of their mental health condition. Once again, this may be clearer in our data because we asked about discrimination specifically and not about stigma generally. Unlike the implications of concepts of self-stigma, it may be argued that this anticipated discrimination is not unrealistic and that in some instances it is an active choice made by people with a diagnosis of schizophrenia to deal with psychic threat. For example, in an ethnographic study, Jenkins \& Carpenter (2005) found that respondents took many positive steps to deal with the discrimination they faced in order to preserve their own integrity. 


\section{Positive discrimination}

We coded the examples in our data as 'negative', 'neutral' and 'positive' for each question and used the method of constant comparison to look at differences between them (Strauss \& Corbin, 1990). We noted the responses to the Likert scales. But when we looked again at the 'positive' examples, it was clear that they differed in nature from the much more frequent negative ones. Connotatively, many of the negative examples were 'strong'; they concerned rejection, teasing, humiliation, abuse and so on. The 'positive' examples, on the other hand, never contained such strong connotations, even when real benefit was conferred such as special treatment in getting housing. The language that the respondents used simply was not semiotically the same. Positive examples generally referred to other people treating the participant well they were treated 'nicely', with kindness, with understanding. This is the way people generally respond to each other in a civil society (or are supposed to).

It is hardly surprising if our respondents wish to be treated like anyone else. The surprising thing is that they considered this as an 'advantage' of their diagnosis. They did not say that such examples amounted to 'no different treatment' which could be argued was the case. They said that being treated with civility corresponded to advantageous treatment. In the absence of discrimination that was expected, people with mental illness feel grateful. Other members of society see no need to be grateful if they are treated with civility.

\section{Limitations}

Our study could be criticised as having a Western bias. All our participants came from large centres of population and the diagnostic criteria were Western ones, albeit devised with advice from over the globe. People who would receive a diagnosis of schizophrenia according to these conditions might not so receive it were they living in less urban situations. This may be one reason why we found so few cross-cultural differences.

The other group of people who are 'missing' in our analysis are those not engaged with treatment even in the sites that we studied. It is, by definition, difficult to do research with people who are 'not engaged' with services. But there may be differences. For example, rejection of diagnoses and of the identity of 'psychiatric patient' may have implications for the extent of stigma and discrimination and responses to it which warrant further research.

\section{Conclusion}

For the sample studied here, a diagnosis of schizophrenia is reported as eliciting disadvantage in all the domains of everyday life covered by the DISC. We conclude that the disadvantages experienced by people with a diagnosis of schizophrenia encompass nearly all domains of life and in all societies comparable to those studied here. Reported 'positive' discrimination amounts to no more than normal interaction in social life but this is interpreted by respondents as a positive advantage of their diagnosis because discrimination is what they expect.

\section{Declaration of Interests}

This study was supported by the South London and Maudsley Charitable Trust.

\section{References}

Ahuvia A (2001). Traditional, interpretive and reception based content analysis: improving the ability of content analysis to address issues of pragmatic and theoretical concern. Social Indicators Research 54, 139-172.

Angermeyer MC, Beck M, Matschinger H (2006). Determinants of the public's preference for social distance from people with schizophrenia. Canadian Journal of Psychiatry 48, 663-668.

Angermeyer M, Beck M, Deitriech S, Holzinger A (2004). The Stigma of Mental Illness: Patients' Anticipations and Experiences. International Journal of Social Psychiatry 50, 153-162.

Barbour R (2001). Checklists for improving rigour in qualitative research: a case of the tail wagging the dog? BMJ 322, 1115-1117.

Boyatzis RE (1998). Transforming Qualitative Information: Thematic Analysis and Code Development. Sage: Thousand Oaks, California, London.

Braun V, Clarke V (2006). Using thematic analysis in psychology. Qualitative Research in Psychology 3, 77-101.

Brohan E, Slade M, Clement S, Thornicroft G (2010). Experiences of mental illness stigma, prejudice and discrimination: a review of measures. BMC Health Services Research 10, 80.

Buizza C, Schulze B, Rossi B, Ghilardi and Pioli (2007). The stigma of schizophrenia from patients' and relatives' view: A pilot study in an Italian rehabilitation residential care unit. Clinical Practice and Epidemiology in Mental Health doi:10.1186/1745-0179-3-

Cechnicki, Angermeyer MC, Bielańska A (2010). Anticipated and experienced stigma among people with schizophrenia: its nature and correlates. Social Psychiatry and Psychiatric Epidemiology, doi: 10.1007/s00127-010-0230-2

Corrigan PW, Markowitz FE, Watson A, Rowan D, Kubiak MA (2003). An attribution model of public discrimination towards persons with mental illness. Journal of Health and Social Behaviour 44, 162-179.

Cumming E, Cumming J (1957). Closed Ranks: An Experiment in Mental Health Education. Harvard University Press: Cambridge, MA. 
Department of Health, England (2003). Attitudes to Mental Illness. Taylor Nelson Sofres: London.

Falk G (2001). Stigma: How We Treat Outsider's. Prometheus Books, New York.

González-Torres, Rodrigo Oraa Maialen Arístegui Aranzazu Fernández-Rivas Jose Guimon (2006). Social Psychiatry and Psychiatric Epidemiology, 42, 14-23.

Hayward P, Bright JA (1997). Stigma and mental illness: A review and critique. Journal of Mental Health 6, 345-354.

Jenkins JH, Carpenter-Song E (2005). The new paradigm of recovery from schizophrenia: cultural conundrums of improvement without cure. Culture Medicine and Psychiatry 29, 379-413.

Kolodziej M, Johnson B (1996). Interpersonal contact and acceptance of persons with psychiatric disorders: a research synthesis. Journal of Consulting and Clinical Psychology 64, 1387-1396.

Kurihara T, Kato M, Sakamoto S, Reverger R, Kitamura T (2000). Public attitudes towards the mentally ill: a cross-cultural study between Bali and Tokyo. Psychiatry and Clinical Neuroscience 54, 547-52.

Link BG, Cullen FT (1986). Contact with the mentally ill and perceptions of how dangerous they are. Journal of Health and Social Behaviour 27, 289-303.

Link BG, Phelan JC (2001). Conceptualizing stigma. Annual Review of Sociology 27, 363-385.

Link BG, Struening EL, Neese-Todd S, Asmussen S, Phelan $\mathbf{M}$ (2001). Stigma as a barrier to recovery: the consequences of stigma for the self-esteem of people with mental illnesses. Psychiatric Services 52, 1621-1626.

Markowitz FE (1998). The effects of stigma on the psychological well-being and life satisfaction of persons with mental illness. Journal of Health and Social Behaviour 39, 335-347.

QSR (2002). NVivo 2. QSR International Pty Ltd: Victoria, Australia.

Rose D, Sweeney A, Leese M, Burns T, Catty J, Wykes T (2009). Developing a user-generated measure of continuity of care: brief report. Acta Psychiatrica Scandinavica 119, 320-324.

Rose D, Thornicroft G (2010). Service user perspectives on the impact of a mental illness diagnosis. Epidemiologia e Psichiatria Sociale 19, 140-47.

Rose DS, Knight M, Fleischmann P, Thornicroft G, Sidhu R, Kassam A, Bhugra B, Pinfold V. (2007). Public and Media Perceptions of Risk and Violence from People with Mental Ill Health. Commission for Services Improvement: London.

Sartorius N, Kuyken W (1994). Translation of Health Status Instruments. In Quality of Life Assessment in Health Care Settings (ed. J Orley and J Kuyken), pp. 97-112, Springer-Verlag: Berlin.

Scheff TJ (1966). Being Mentally Ill: A Sociological Theory. Aldine: Chicago, IL.

Schomerus G, Matschinger H, Kenzin D, Breier P, Angermeyer MC (2006). Public attitudes towards mental patients: a omparison between Novosibirsk, Bratislava and German Cities. European Psychiatry 2, 436-441.

Slade M (2009). Personal Recovery and Mental Illness. Cambridge University Press: Cambridge.

Slade M, Amering M, Oakes L (2008). Recovery; an international perspective. Epidemiologia e Psichiatria Sociale 17, 128-137.

Star SA (1955). The Public's Ideas about Mental Illness. National Opinion Research Centre, University of Chicago (unpublished monograph).

Strauss AL, Corbin JM (1990). Basics of Qualitative Research: Grounded Theory Procedures and Techniques. Sage: Newbury Park, California.

Thornicroft G (2006). Shunned: Discrimination against People with Mental Illness. Oxford University Press: Oxford.

Thornicroft G, Brohan E, Rose DS, Sartorius N, Leese M, the INDIGO Study Group (2009). Global pattern of experienced and anticipated discrimination against people with schizophrenia. Lancet 373, 408-415. 